\title{
Sexually inexperienced anestrous goats are able to exhibit sexual behaviours exposed to sexually active bucks
}

\author{
Jessica Anabel Loya-Carrera - Sergio Ramírez - Angélica Terrazas • \\ Horacio Hernández • Jesús Vielma • Gerardo Duarte • Ilda Graciela Fernández
}

\begin{abstract}
JA Loya-Carrera - S Ramírez - H Hernández - J Vielma
- G Duarte - IG Fernández (Corresponding author)

Centro de Investigación en Reproducción Caprina, Posgrado en Ciencias Agrarias, Universidad Autónoma Agraria Antonio Narro, Periférico Raúl López Sánchez, C.P. 27054, Torreón, Coahuila, México.

e-mail: ilda_fernandez_garcia@yahoo.com.mx
\end{abstract}

\author{
A Terrazas \\ Departamento de Ciencias Pecuarias, Facultad de Estudios \\ Superiores Cuautitlán, Universidad Nacional Autónoma de \\ México. Km 2.5 Cuautitlán-Teoloyucan San Sebastián \\ Xhala, Cuautitlán Izcalli, Edo. México, C.P. 54714.
}

Received: December 28, 2016 • Revised: February 02, $2017 \cdot$ Accepted: February 20, 2017

\begin{abstract}
The aim of this study was to determine whether sexually inexperienced females could display proceptivity and receptivity behaviours as the experienced in the first exposure to males. Three groups of females ( $n=9$ each) were used: i) sexually inexperienced, ii) with complete sexual experience, and iii) with limited sexual experience. Three male goats were subjected to photoperiodic treatment for 2.5 months of long days to stimulate their sexual activity during the natural sexual rest (March-April). During anestrous season, females were exposed to photo-stimulated males. Sexual behaviours were recorded during the first three days post-introduction of the males into female groups, in two daily periods of $20 \mathrm{~min}$ each. Sexually inexperienced females and those with complete sexual experience showed higher tail wagging than those with limited sexual experience $(\mathrm{P}<0.001)$. Sexually inexperienced females displayed higher female-female sniffing and emission of urine than those groups with complete and limited sexual experience $(\mathrm{P}<0.001$ and $\mathrm{P}<0.05$, respectively). Females with limited sexual experience displayed higher female-female mounts than those groups inexperienced and with complete sexual experience $(\mathrm{P}<0.05)$. In addition, females with complete sexual experience displayed higher male-female sniffing than those groups inexperienced and with limited sexual experience $(\mathrm{P}<0.001)$. Receptivity behaviour did not differ between female groups $(\mathrm{P}>0.05)$. We concluded that sexually inexperienced anestrous females display proceptivity and receptivity behaviours as those sexually experienced exposed to photo-stimulated males.
\end{abstract}

Keywords: anovulatory does, Capra hircus, male effect, photoperiod, seasonality

\section{Introduction}

Sexual activity in sheep and goat females is regulated by photoperiod (Duarte et al 2008; Abecia et al 2015). In these females the period of sexual activity is known as natural reproductive season, and another one of sexual inactivity is called seasonal anestrous (Delgadillo et al 1991, 1992; Restall 1992; Chemineau et al 2006; Duarte et al 2008). If sheep and goat females are exposed suddenly to a male during seasonal anestrous, in a relatively short time they exhibit sexual behaviours. This technique of sexual biostimulation is known as the male effect (Shelton 1960; Martin et al 1986; Chemineau 1987; Delgadillo et al 2009).

In the mammals, it is known that the females in sexual activity display stereotyped behaviours towards the male that are expressed in two motivational phases, and are known as proceptivity and receptivity (Beach 1976). During the proceptive phase, females display behaviours in order to attract the attention of the male, and initiate sexual contact with him; while in the receptive phase, females allow the consummation of the sexual encounter with the male (acceptance of mounts with intromission; Beach 1976; Price 1985; Fabre-Nys and Gelez 2007). For example, sexually active sow exhibits proceptivity behaviours when is in physical contact with the boar, in addition they display headbutting, and sniffs the flanks and ano-genital region of the boar (Hemsworth 1985). In contrast, in ewes during the same phase, they exhibit movements with the head towards to the male, remain close to him, and exhibit tail wagging (Gonyou 1991; Gelez and Fabre-Nys 2004; Gelez et al 2004). In sheep, sexually inexperienced females, i.e. those who have not had socio-sexual contact with males are less proceptive and receptive than those with sexual experience (Gelez et al 2004; Hawken et al 2008). In comparison, sexually experienced goats, i.e. when females have had socio-sexual contact with males, during natural or induced estrus, they exhibit proceptivity behaviours such as tail wagging and female-female mounts (Llewelyn et al 1993; Imwalle and 
Katz 2004). In fact, sexually experienced anestrous females are more receptive when exposed to photo-stimulated males than non-photo-stimulated (Delgadillo et al 2002; RivasMuñoz et al 2007; Loya-Carrera et al 2014; Muñoz et al 2016).

To our knowledge, there are no studies in goats which have reported the effect of lack of sexual experience in females neither the restriction of sexual experience to display of proceptivity behaviours during seasonal anestrous when exposed to photo-stimulated males. Therefore, the hypothesis in the present study states that sexually inexperienced goats, during anestrous season, could display lower sexual behaviours in their first exposure to males than sexually experienced goats. The objective of the present study was to determine whether sexually inexperienced females, in their first exposure to photo-stimulated males, could exhibit sexual behaviours of proceptivity and receptivity as those sexually experienced goats.

\section{Materials and Methods}

\section{Ethical note}

The management of the females and males in the present study was carried out following the protocol of the Norma Oficial Mexicana, according to specifications for the production, care and management of laboratory animals (SAGARPA 2001). The early separation of the kids from their mothers, and artificial breastfeeding that they received did not disrupt normal growth and development in these females.

Animals and description of experimental groups

Twenty-seven creole goat kids were born on January $10 \pm 2$ days (mean value \pm standard error of mean) from the Laguna region in the State of Coahuila (latitude $26^{\circ} 23^{\prime} \mathrm{N}$ and longitude $104^{\circ} 47^{\prime} \mathrm{W}$ ) during the natural breeding season were used. The goat kids were kept at all times in housing. The goat kids were separated from their mothers at 3 days of age, and were fed with goat's milk through an artificial breastfeeding system, which has shown have not negative effects on the development and weaning of goat kids ( $\mathrm{Lu}$ and Potchoiba 1988; Luo et al 2000). In addition, were given forage and water ad libitum. The goat kids remained in these conditions until 40 days of age. Then, females were randomly distributed into three groups. The first, sexually inexperienced females $(n=9)$ were kept isolated from males in a pen of $5 \times 5 \mathrm{~m}$. The second, with complete sexual experienced females $(n=9)$ were maintained in complete permanent contact with two vasectomized males. These females and males were placed in a single pen $(5 \times 5 \mathrm{~m})$. The third, with limited sexual experienced females $(n=9)$ was maintained in restricted permanent contact with two vasectomized males. Females were placed in a pen $(5 \times 5 \mathrm{~m})$ adjacent to vasectomized males $(5 \times 2 \mathrm{~m})$, separated by a division of wire-mesh. Vasectomized males were 2 years old on average. Females with complete and limited sexual experience remained in contact with vasectomized males since artificial breastfeeding with bottles was suspended (40 days old), until the next natural breeding season when females were 12 months old. Afterwards, the vasectomized males were removed from the pens. Females remained in these conditions until behavioural measurements were carried out.

Females were fed with alfalfa hay ad libitum (18\% crude protein, $1.95 \mathrm{Mcal} / \mathrm{kg}$ ) and commercial concentrate (18\% crude protein; $2.05 \mathrm{Mcal} / \mathrm{kg}$ ) according to their nutritional requirements from weaning until the end of the study. Vasectomized males were fed with alfalfa hay ad libitum (18\% crude protein; $1.95 \mathrm{Mcal} / \mathrm{kg})$ and $300 \mathrm{~g}$ of commercial concentrate ( $14 \%$ crude protein, $2.5 \mathrm{Mcal} / \mathrm{kg}$ ). For females and males drinking water and mineral salts $(12 \%$ phosphorus and $11 \%$ calcium) were always available.

Treatment of artificial photoperiod applied to males

In order to induce an increase in sexual behaviour, odor, vocalizations and sperm production in males during the natural sexual rest (March-April; Delgadillo et al 2002), a treatment of artificial photoperiod was applied. Entire males $(n=3)$ of 3 years of age on average were used. Males were housed in outdoor pen $(5 \times 5 \mathrm{~m})$ in order to receive the treatment of artificial photoperiod (with lamps of $65 \mathrm{~W}$ ). Light intensity was at least $300 \mathrm{~lx}$ at the level of the eyes of the males. The treatment of long days applied to the males was for 2.5 months (16 h of light/day), starting on November 1 to January 15 (Figure 1). From January 16 the males perceived the natural photoperiod.

Preparation of females

In goats of this region, the seasonal anestrous is from March to September (Duarte et al 2008). Therefore, in the month of March, when females were 14 months old, they were submitted to an evaluation to determine their anovulatory status. The anovulation was determined with the help of studies of ultrasonography, and was resolved when corpora lutea were not detected. The ultrasonography studies were performed on March 10 and 20 before introducing photo-stimulated males into three groups of females. The echography used was an Aloka SSD-500 (Tokyo, Japan) with a $7.5 \mathrm{MHz}$ transducer. In addition, three days before beginning the experiment, and based on the scale described by Walkden-Brown et al (1997), body condition score was measured in sexually experienced females, with complete 
and limited sexual experience $(2.6 \pm 0.08,2.5 \pm 0.09$ and 2.5 \pm 0.07 , respectively; $\mathrm{P}>0.05$ ).

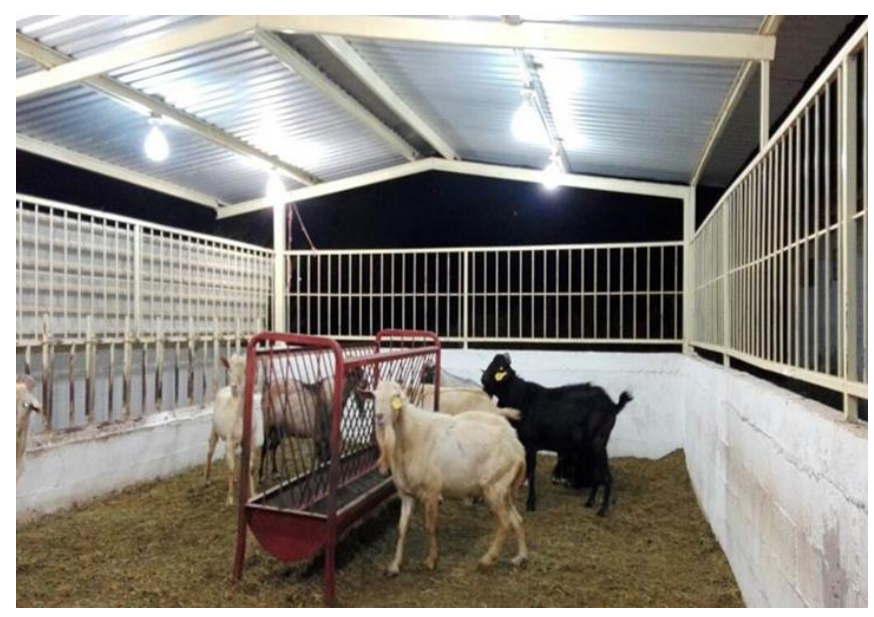

Figure 1 Males were submitted to a treatment of artificial long days, light intensity was at least $300 \mathrm{~lx}$ at the level lateral of the eyes of the males. The treatment of artificial long days applied to the males was for 2.5 months ( $16 \mathrm{~h}$ of light/day) from November 1 to January 15.

\section{Male effect}

On March 25 (day 0; 08:00 h), a photo-stimulated male was placed in contact with each group of females (sexually inexperienced, with completed and limited sexual experience). Afterwards, the males were exchanged in each group of females in the morning (08:00) and in the afternoon (18:00). This management was maintained for 15 days.

Behavioural measurements
For males, behavioural measure were performed with focal continued observation (Martin and Bateson 2007), on days 0,1 and 2, for a period of $20 \mathrm{~min}$ (08:00 to 08:20 and 18:00 to 18:20). Individual total number of occurrences of ano-genital sniffing, nudging, self-urination, flehmen response, mounting attempts, mounts without and with intromission were recorded to verify that males were sexually active. During behavioural measure all males in contact with the three groups of females displayed sexual activity (Table 1; Figure 2 and Figure 3; Flores et al 2000; Loya-Carrera et al 2014).

Regarding to females we decided that measurements should be taken only during the first three days postintroduction of males into female groups, since it has been demonstrated to be the time lapse sufficient to photostimulated males induce sexual response in anestrous females through the male effect (Flores et al 2000; Rivas-Muñoz et al 2007; Bedos et al 2010). So that females were observed with a similar method as the described for the males, and the frequency of the next proceptivity behaviours were recorded: tail wagging, female-female sniffing, female-male sniffing, female-female mounts, and emission of urine (Table 1). Receptive sexual behaviour registered was acceptance of the mount with intromission (Table 1). A female was considered as receptive when she remained immobile and accepted to be mounted by the male (Chemineau et al 1992). In addition, frequency of vocalizations (high bleating) was recorded. The observations were videotaped using a video camera (SONYV8, Japan). The video-recordings were analyzed later in the laboratory using the program Observer Video Pro version 4.0 (Noduls, The Netherlands).

Table 1 Sexual behaviours in male goats in contact with females.

\begin{tabular}{|c|c|}
\hline Behaviour & Description \\
\hline \multicolumn{2}{|l|}{ Male } \\
\hline Nudging & He approaches the female sometimes vocalizing and lowering his head \\
\hline Ano-genital sniffing & $\begin{array}{l}\text { He approaches his nose near the female }(<0.005 \mathrm{~m}) \text { smelling her genital or anal } \\
\text { areas }\end{array}$ \\
\hline Mounting attempts & He attempts to mount the female, but does not place its body on top \\
\hline Flehmen response & $\begin{array}{l}\text { After smelling and/or tasting the females' urine he lifts its head and upper the lip } \\
\text { up }\end{array}$ \\
\hline Self-urination & He urinates himself by turning his penis onto his face \\
\hline $\begin{array}{l}\text { Mounts without and with } \\
\text { intromission }\end{array}$ & He mounts the female either penetrating or not penetrating her \\
\hline \multicolumn{2}{|l|}{ Female } \\
\hline Tail wagging & $\begin{array}{l}\text { She moves its tail quickly side ways. The frequency is measured by the number } \\
\text { of episode in a time unit }\end{array}$ \\
\hline Female-female sniffing & When a female approaches another female in order to smell a part of her body \\
\hline Female-female mounts & A female climbs up getting on top of another female \\
\hline Emission of urine & She does urinate \\
\hline $\begin{array}{l}\text { Acceptance of mounts with } \\
\text { intromission }\end{array}$ & A female stays still, allowing to be mounted and penetrated by a male \\
\hline
\end{tabular}


Statistical analysis

The total frequency of behaviors as tail wagging, female-female sniffing, female-male sniffing, female-female mounts, acceptance of mounts, vocalizations, and emission of urine were compared between groups of females using the Chi-square test for multiple group comparison and with the Fisher exact probability test. Statistical analysis was carried out using the statistical package SYSTAT version 13.00.05 (Systat Software, Inc., Chicago, IL, USA).

\section{Results}

Proceptivity behaviours

Sexually inexperienced females and the group with complete sexual experience displayed higher frequency of tail wagging than those with limited sexual experience $(\mathrm{P}<0.001$, Figure 4). Likewise, sexually inexperienced females displayed higher female-female sniffing $(\mathrm{P}<0.001$; Figure 4) than those groups with complete and limited sexual experience. Furthermore, sexually inexperienced females displayed higher emission of urine $(\mathrm{P}<0.05$; Figure 4$)$ than those groups with complete and limited sexual experience. In contrast, the group with limited sexual experience displayed higher female-female mounts $(\mathrm{P}<0.05$; Figure 4$)$ than those groups inexperienced and with complete sexual experience. In addition, the group with complete sexual experience displayed higher male-female sniffing $(\mathrm{P}<0.001$; Figure 4$)$ than those groups inexperienced and with limited sexual experience.

\section{Receptivity behavior}

The frequency of acceptance of the mounts did not differ ( $\mathrm{P}>0.05$; Figure 4 and Figure 5) between the three groups of females.

\section{Other behavior}

Sexually inexperienced females emitted higher vocalizations $(\mathrm{P}<0.001$; Figure 4$)$ than those groups with complete and limited sexual.

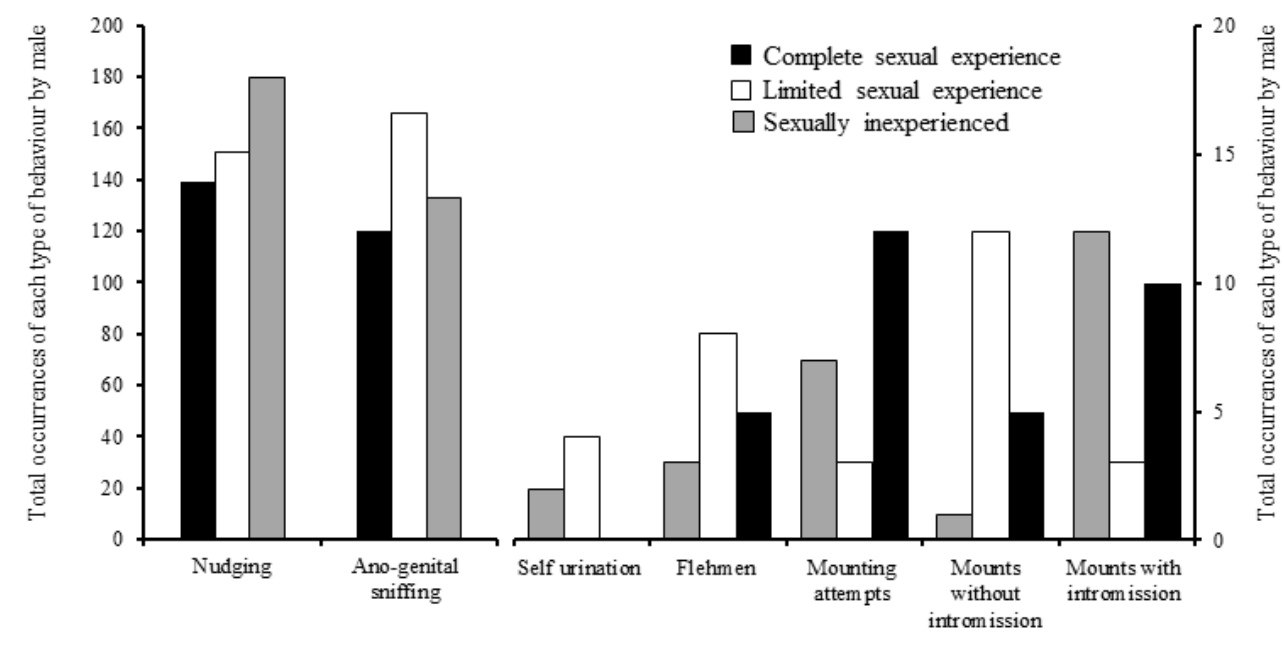

Figure 2 Individual occurrences of ano-genital sniffing, nudging, flehmen response, self-urination, mounting attempts, mounts with and without intromission in males interacting with sexually inexperienced females (gray bars), with complete sexual experienced females (dark bars) and with limited sexual experienced females (white bars). Sexual behaviour of males was observed from 08:00 to 08:20 and 18:00 to 18:20 on days 0,1 , and 2 after introduction of males in the groups of females. Males were rendered sexually active by exposure to artificial long days (16 h of light by day) from November 1 to January 15 .

\section{Discussion}

The results of the present study indicate that sexually inexperienced anestrous goats were able to display proceptivity and receptivity sexual behaviours, as those sexually experienced goats, when they were exposed for the first time to photo-stimulated males. We considered in our study that in spite of the fact that sexually inexperienced females were exposed to a photo-stimulated male suddenly at 14 months of age, lack of sexual experience or familiarity to males did not prevent them to display sexual behaviours. In fact, sexual behaviour was similar between sexually inexperienced goats, and in those were already familiarzed with the male completely or restricted from weaning. Our results also indicate that lack of sexual experience did not affect the response to the male effect during seasonal anestrous. This is relevant because it indicates that there are innate factors involved in the acceptance of mounts (receptivity) wich are activated when females receive sensorial stimuli, in this case sexual biostimulation by photo- 
stimulated males (Pfaus et al 2001; Delgadillo et al 2002). Then, when females exhibit proceptivity behaviours learning factors are involved that facilitates mating (Agmo 1999; Pfaus et al 2001; Gelez et al 2004).

a)

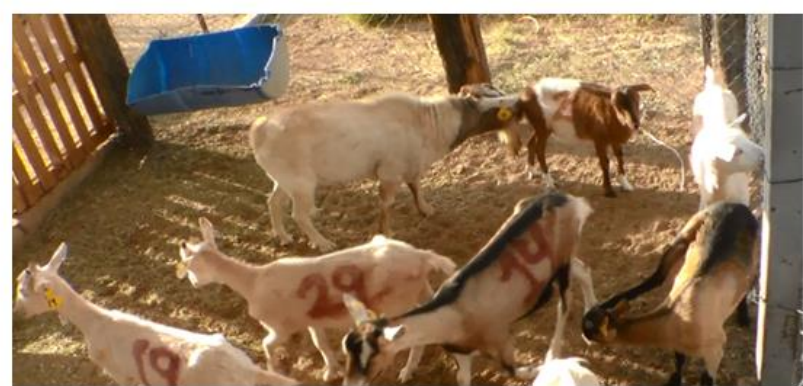

b)

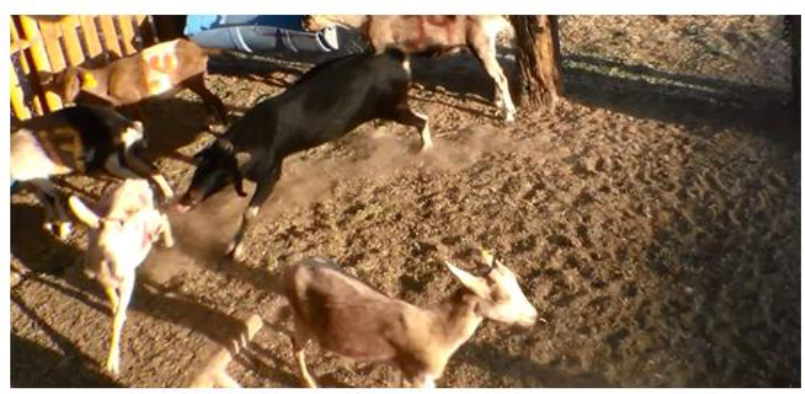

c)

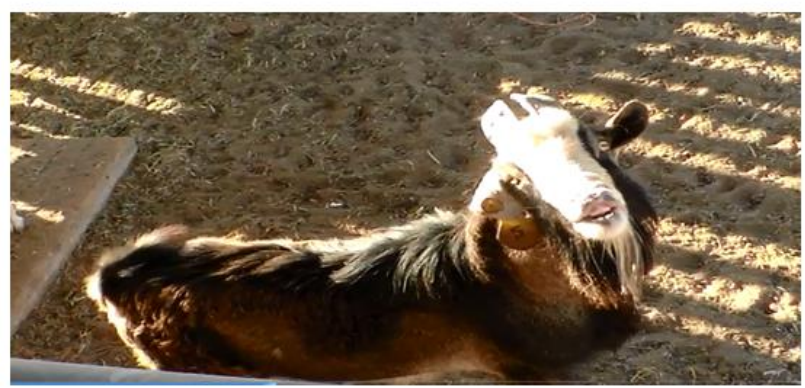

Figure 3 Sexual behaviours of a) ano-genital sniffing, b) nudging, and c) flehmen response exhibited by photo-stimulated males interacting with anestrous females. Males were rendered sexually active by exposure to artificial long days ( $16 \mathrm{~h}$ of light by day) from November 1 to January 15.

In the present study, sexual behaviour of tail wagging was more frequent in the groups with sexual inexperience and complete sexual experience than in the restricted females group. These results are in accordance with literature, because tail wagging also was observed, and did not differ between sexually inexperienced and experienced anestrous ewes (Hawken et al 2008). In addition, these behaviour also was observed in goats that were in induced estrus during the proceptive phase (Imwalle and Katz 2004; Haulenbeek and Katz 2011), and in females that were in natural estrus, displaying not only tail wagging but also remaining close to the males (Llewelyn et al 1993). According to our results and those studies mentioned above, it is shown that tail wagging is a characteristic sign of estrus in both sheep and goats.
Therefore, ewe and goat females display tail wagging as a visual signal to establish communication with the males.

The female-female sniffing was more observed in sexually inexperienced goats than in complete and limited sexual experience female groups. Perhaps this response was due to fact that sexually inexperienced goats were more familiarized with other females than males, and then they redirected such behaviour, as has been demonstrated in male goats (Ungerfeld et al 2014).

The homosexual behaviours, i.e. when males exhibit sexual behaviours to individuals of the same sex, are more frequent in males that had been isolated from females (Ungerfeld et al 2014). In our study, anestrous females with limited sexual experience exhibited more female-female mounts than sexually inexperienced goats and those with complete sexual experience, which could be associated with an attempt to attract attention of the male, and initiate a sexual interaction, perhaps caused by previous restriction to males (Beach 1976; Shearer and Katz 2006). Llewelyn et al (1993) found that behaviour of female-female mounts was exhibited by goats with higher social rank which were in estrus during the natural breeding season also in order to attract attention of males.

In regards to female-male sniffing, females with complete sexual experience exhibited more often this behaviour than sexually inexperienced and those with limited sexual experience. This response was probably due to the fact that females already had sexual experience and identified easily the presence of males.

The receptive behaviour (acceptance of mounts) did not differ between the three groups of goats exposed to photo-stimulated males. In addition, this response was similar to that reported in sexually inexperienced goats (isolated from males) and in sexually experienced goats without sexual intromission before the male effect (Fernández et al 2011). Likewise, receptivity exhibited by sexually inexperienced females during their first exposure to photo-stimulated males was similar to exhibited by females with previous sexual experience, and exposed to photostimulated males (Rivas-Muñoz et al 2007; Luna-Orozco et al 2008; Loya-Carrera et al 2014).

In contrast, our results differed from those of Delgadillo et al (2012), where sexually inexperienced females and exposed for the first time to vocalizations of males displayed lower acceptance of mounts than those experienced. These results suggest that total contact with males is necessary for females to exhibit sexual behaviours (Delgadillo et al 2012). In our study we found that sexually inexperienced females emitted more vocalizations and emissions of urine than other two groups of goats. This response was probably due to the fact that females suffered stress when they were placed in contact with the males for the first time, as was observed in ewes (Gelez et al 2004). 
Furthermore, the emissions of urine can also be considered as proceptivity behaviour as was demonstrated in mice (Mus musculus, Dizinno et al 1978). Also it has been shown that critical situations such as exposure to new stimuli (Chojnacki et al 2014), social isolation (Terrazas et al 2012) and hunger induce an increase in vocalizations, and eliminations (Poindron et al 2007). It has also been shown that goat females are more sensitive to respond that way than males (Terrazas et al 2012; Chojnacki et al 2014).
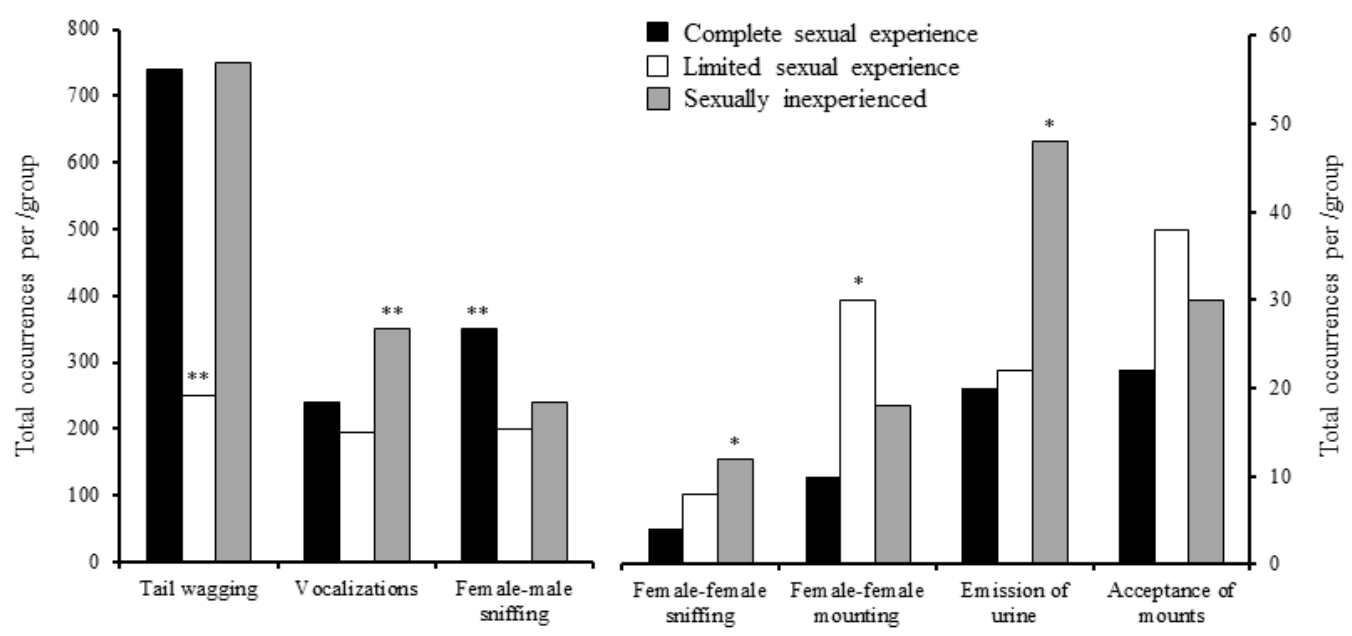

Figure 4 Frequencies of tail wagging, female-female sniffing, female-female mounts, female-male sniffing, acceptance of mounts, vocalizations and emission of urine in sexually inexperienced females (gray bars), with complete sexual experienced females (dark bars), and with limited sexual experienced females (white bars). Sexual behaviour of females was observed from 08:00 to 08:20 and 18:00 to 18:20 on days 0,1 and 2 after introduction of males in the groups of females. Males were rendered sexually active by exposure to artificial long days (16 h of light by day) from November 1 to January $15 . * *(\mathrm{P}<0.001)$.

In the present study, our females deprived of the male presence before the male effect displayed sexual behaviours as those with previous experience. This response was due to the fact that females were exposed to males that exhibited high sexual behaviour. It is reported in literature that photostimulated males which exhibit a high level of sexual behaviour as nudging, ano-genital sniffing, self-urination, flehmen response, mounting attempts, and mounts with intromission are efficient for inducing sexual response in anestrous females. On the other hand, those males with low sexual behavior are inefficient to induce sexual response in anestrous females (Delgadillo et al 2002; Loya-Carrera et al 2014; Muñoz et al 2016). In addition, photo-stimulated males exhibiting sexual behaviour during natural sexual rest inducing a high percentage $(>92 \%)$ of estrus (receptivity) in sexually experienced females (Rivas-Muñoz et al 2007; Luna-Orozco et al 2008). Finally, the results mentioned above suggest that photo-stimulated males first induce the proceptive phase, and then the receptive phase (acceptance of mounts) in anestrous females.

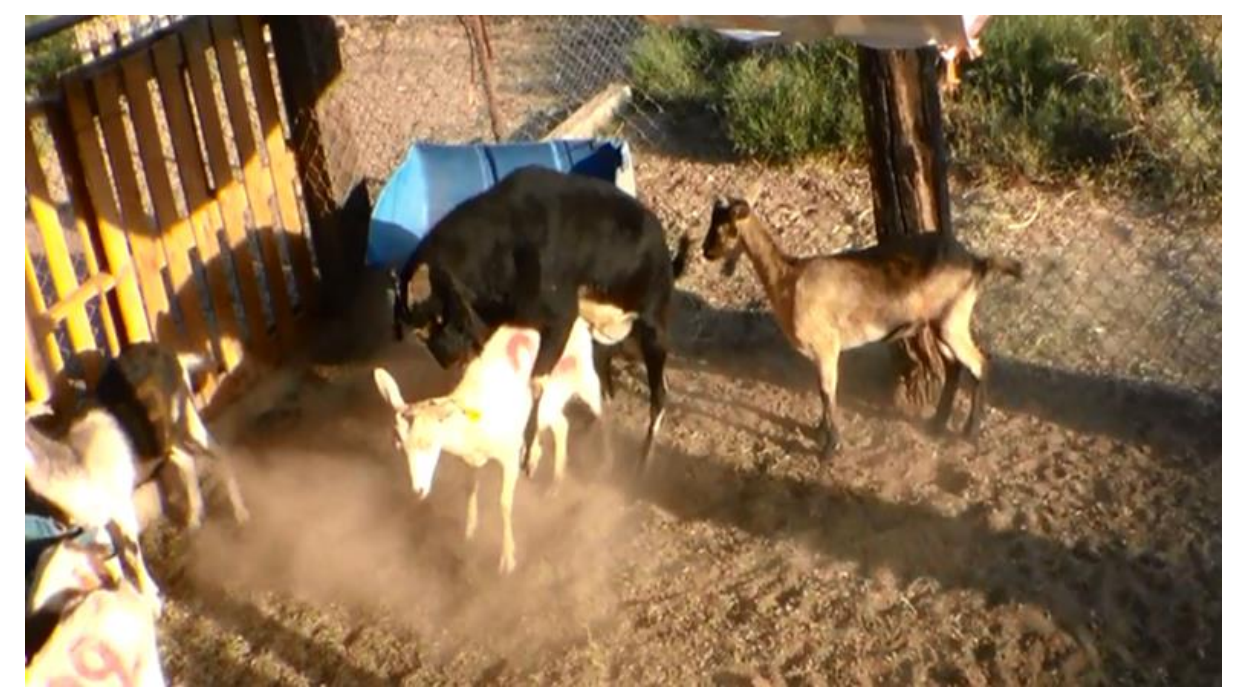

Figure 5 Receptivity sexual (acceptance of the mount) in sexually inexperienced females exposed to photo-stimulated males. Males were rendered sexually active by exposure to artificial long days ( $16 \mathrm{~h}$ of light by day) from November 1 to January 15 . 


\section{Conclusions}

Sexually inexperienced females during anestrous season display proceptivity and receptivity behaviours as those sexually experienced when exposed to photostimulated males for the first time through the male effect.

\section{Acknowledgements}

The authors are grateful to all members of the Centro de Investigación en Reproducción Caprina (CIRCA) of the Universidad Autónoma Agraria Antonio Narro for their support during the experiment. Jessica A. Loya-Carrera was supported by a scholarship of CONACyT during her doctoral studies.

\section{References}

Abecia JA, Chemineau P, Flores JA, Keller M, Duarte G, Forcada F, Delgadillo JA (2015) Continuous exposure to sexually active rams extends estrous activity in ewes in spring. Theriogenology 84:1549-1555.

Agmo A (1999) Sexual motivation-an inquiry into events determining the occurrence of sexual behavior. Behavioural Brain Research 105:129-150.

Beach FA (1976) Sexual attractivity, proceptivity, and receptivity in female mammals. Hormones and Behavior 7:105-138.

Bedos M, Flores JA, Fitz-Rodríguez G, Keller M, Malpaux B, Poindron P, Delgadillo JA (2010) Four hours of daily contact with sexually active males is sufficient to induce fertile ovulation in anestrous goats. Hormones and Behavior 58:473-477.

Chemineau P (1987) Possibilities for using bucks to stimulate ovarian and oestrus cycles in anovulatory goats-a review. Livestock Production Science 17:135-147.

Chemineau P, Daveau A, Maurice A, Delgadillo JA (1992) Seasonality of oestrus and ovulation is not modified by subjecting female Alpine goats to a tropical photoperiod. Small Ruminant Research 8:299-312.

Chemineau P, Pellicer-Rubio MT, Lassoued N, Khaldi G, Monniaux D (2006) Male-induced short oestrous and ovarian cycles in sheep and goats: a working hypothesis. Reproduction Nutrition Development 46:417-429.

Chojnacki RM, Vas J, Andersen IL (2014) The effects of prenatal stocking densities on the fear responses and sociality of goat (Capra hircus) kids. PLoS One 9:e94253.

Delgadillo JA, Flores JA, Véliz FG, Hernández HF, Duarte G, Vielma J, Poindron P, Chemineau P, Malpaux B (2002) Induction of sexual activity of lactating anovulatory female goats using male goats treated only with artificial long days. Journal of Animal Science 80:2780-2786.

Delgadillo JA, Gelez H, Ungerfeld R, Hawken PAR, Martin GB (2009) The 'male effect' in sheep and goats-Revisiting the dogmas. Behavioural Brain Research 200:304-314.

Delgadillo JA, Leboeuf B, Chemineau P (1991) Decrease in the seasonality of sexual behavior and sperm production in bucks by exposure to short photoperiodic cycles. Theriogenology 36:755770.

Delgadillo JA, Leboeuf B, Chemineau P (1992) Abolition of seasonal variations in semen quality and maintenance of sperm fertilizing ability by photoperiodic cycles in goat bucks. Small Ruminant Research 9:47-59.

Delgadillo JA, Vielma J, Hernandez H, Flores JA, Duarte G, Fernández IG, Keller M, Gelez H (2012) Male goat vocalizations stimulate the estrous behavior and LH secretion in anestrous goats that have been previously exposed to bucks. Hormones and Behavior 62:525-530.

Dizinno G, Whitney G, Nyby J (1978) Ultrasonic vocalizations by male mice (Mus Musculus) to female sex pheromone: experiential determinants. Behavioral Biology 22:104-113.

Duarte G, Flores JA, Malpaux B, Delgadillo JA (2008) Reproductive seasonality in female goats adapted to a subtropical enviroment persist independently of food availability. Domestic Animal Endocrinology 35:362-370.

Fabre-Nys C, Gelez H (2007) Sexual behavior in ewes and other domestic ruminants. Hormones and Behavior 52:18-25.

Fernández IG, Luna-Orozco JR, Vielma J, Duarte G, Hernández H, Flores JA, Gelez H, Delgadillo JA (2011) Lack of sexual experience does not reduce the responses of $\mathrm{LH}$, estrus or fertility in anestrous goats exposed to sexually active males. Hormones and Behavior 60:484-488.

Flores JA, Véliz FG, Pérez-Villanueva JA, Martínez de la Escalera G, Chemineau P, Poindron P, Malpaux B, Delgadillo JA (2000) Male reproductive condition is the limiting factor of efficiency in the male effect during seasonal anestrus in female goats. Biology of Reproduction 62:1409-1414.

Gelez H, Archer E, Chesneau D, Lindsay D, Fabre-Nys C (2004) Role of experience in the neuroendocrine control of ewes' sexual behavior. Chemical Senses 29:555-563.

Gelez H, Fabre-Nys C (2004) The "male effect" in sheep and goats: a review of the respective roles of the two olfactory systems. Hormones and Behavior 46:257-271.

Gonyou HW (1991) Behavioral methods to answer questions about sheep. Journal of Animal Science 69:4155-4160.

Haulenbeek AM, Katz LS (2011) Female tail wagging enhances sexual performance in male goats. Hormones and Behavior 60:244247.

Hawken PAR, Evans ACO, Beard AP (2008) Prior exposure of maiden ewes to rams enhances their behavioural interactions with rams but is not a pre-requisite to their endocrine response to the ram effect. Animal Reproduction Science 108:13-21.

Hemsworth PH (1985) Sexual behavior of gilts. Journal of Animal Science 61:75-85.

Imwalle DB, Katz LS (2004) Divergent roles for estrogens and androgens in the expression of female sexual behavior. Hormones and Behavior 46:54-58.

Llewelyn, CA, Perrie J, Luckins AG, Munro CD (1993) Oestrus in the british white goat: timing of plasma luteinizing hormone surge and changes in behavioural and vaginal traits in relationships to onset of oestrus. British Veterinary Journal 149:171-182.

Loya-Carrera J, Bedos M, Ponce-Covarrubias JL, Hernández H, Chemineau P, Keller M, Delgadillo JA (2014) Switching photo- 
stimulated males between groups of goats does not improve the reproductive response during the male effect. Animal Reproduction Science 146:21-26.

Lu CD, Potchoiba MJ (1988) Milk feeding and weaning of goat kids-A review. Small Ruminant Research 1:105-112.

Luna-Orozco JR, Fernández IG, Gelez H, Delgadillo JA (2008) Parity of female goats does not influence their estrous and ovulatory responses to the male effect. Animal Reproduction Science 106:352-360.

Luo J, Sahlu T, Cameron M, Goetsch AL (2000) Growth of Spanish, Boer $\times$ Angora and Boer $\times$ Spanish goat kids fed milk replacer. Small Ruminant Research 36:189-194.

Martin GB, Oldham CM, Cognie Y, Pearce DT (1986) The physiological response of anovulatory ewes to the introduction of rams. A review. Livestock Production Science 15:219-247.

Martin P, Bateson P (2007) Measuring Behaviour: An Introductory Guide, 3rd edn. Cambridge University Press, pp 48-61.

Muñoz AL, Bedos M, Aroña RM, Flores JA, Hernández H, Moussub C, Briefer EF, Chemineau P, Keller M, Delgadillo JA (2016) Efficiency of the male effect with photostimulated bucks does not depend on their familiarity with goats. Physiology \& Behavior 158:137-142.

Pfaus JG, Kippin TE, Centeno S (2001) Conditioning and sexual behavior: A review. Hormones and Behavior 40:291-321.

Poindron P, Lévy F, Keller M (2007) Maternal responsiveness and maternal selectivity in domestic sheep and goats: the two facets of maternal attachment. Developmental Psychology 49:54-70.

Price EO (1985) Sexual behavior of large domestic farm animals: an overview. Journal of Animal Science 61:62-74.
Restall, BJ (1992) Seasonal variation in reproductive activity in Australian goats. Animal Reproduction Science 27:305-318.

Rivas-Muñoz R, Fitz-Rodríguez G, Poindron P, Malpaux B, Delgadillo JA (2007) Stimulation of estrous behavior in grazing female goats by continuous or discontinuous exposure to males. Journal of Animal Science 85:1257-1263.

SAGARPA. Norma oficial Mexicana NOM-062-ZOO-1999, Especificaciones técnicas para la producción, cuidado y uso de los animales de laboratorio. Diario Oficial de la Federación, 22 de Agosto 2001.

Shearer MK, Katz LS (2006) Female-female mounting among goats stimulates sexual performance in males. Hormones and Behavior 50:33-37.

Shelton M (1960) Influence of the presence of a male goat on the initiation of estrous cycling and ovulations of Angora does. Journal of Animal Science 19:368-375.

SYSTAT 13, 2009. Evanston, IL, USA.

Terrazas A, Hernández H, Delgadillo JA, Flores JA, Ramírez-Vera S, Fierros A, Rojas S, Serafín N (2012) Undernutrition during pregnancy in goats and sheep, their repercussion on mother-young relationship and behavioural development of the young. Tropical and Subtropical Agroecosystems 1:161-174.

Ungerfeld R, Giriboni J, Freitas-de-Melo A, Lacuesta L (2014) Homosexual behavior in male goats is more frequent during breeding season and in bucks isolated from females. Hormones and Behavior 65:516-520.

Walkden-Brown SW, Restall BJ, Scaramuzzi RJ, Martin GB, Blackberry MA (1997) Seasonality in male Australian cashmere goats: long term effects of castration and testosterone or oestradiol treatment on changes in LH, FSH and prolactin concentrations, and body growth. Small Ruminant Research 26:239-252. 